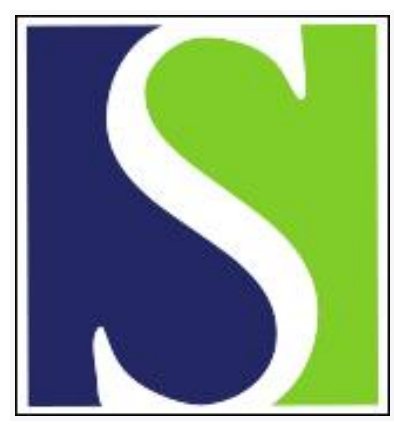

Scand J Work Environ Health 1999;25(5):415-421

https://doi.org/10.5271/sjweh.454

Issue date: Oct 1999

Long-term effects on symptoms by reducing electric fields from visual display units

by Oftedal G, Nyvang A, Moen BE

Key terms: eye symptom; low-frequency electric fields; nervous system symptom; skin symptom; visual property

This article in PubMed: www.ncbi.nlm.nih.gov/pubmed/10569461

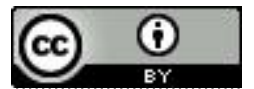




\title{
Long-term effects on symptoms by reducing electric fields from visual display units
}

\author{
by Gunnhild Oftedal, PhD, ${ }^{1}$ Asbjørg Nyvang, RN, ${ }^{2}$ Bente E Moen, DrMed ${ }^{3}$
} Oftedal G, Nyvang A, Moen BE. Long-term effects on symptoms by reducing electric fields from visual display
units. Scand J Work Environ Health 1999:25(5):415-421.

\begin{abstract}
Objectives The purpose of the study was to see whether the results of an earlier study [ie, that skin symptoms were reduced by reducing electric fields from visual display units (VDU)] could be reproduced or not. In addition, an attempt was made to determine whether eye symptoms and symptoms from the nervous system could be reduced by reducing VDU electric fields.

Methods The study was designed as a controlled double-blind intervention. The electric fields were reduced by using electric-conducting screen filters. Forty-two persons completed the study while working at their ordinary job, first 1 week with no filter, then 3 months with an inactive filter and then 3 months with an active filter (or in reverse order). The inactive filters were identical to the active ones, except that their ground cables were replaced by empty plastic insulation. The inactive filters did not reduce the fields from the VDU. The fields were significantly lower with active filters than with inactive filters.

Results Most of the symptoms were statistically significantly less pronounced in the periods with the filters when compared with the period with no filter. This finding can be explained by visual effects and psychological effects. No statistically significant difference in symptom severeness was observed between the period with an inactive filter and the one with an active filter.

Conclusions The study does not support the hypothesis that skin, eye, or nervous system symptoms can be reduced by reducing VDU electric fields.
\end{abstract}

Key terms eye symptoms, low-frequency electric fields, nervous system symptoms, skin symptoms, visual properties.

Some people who work with a visual display unit (VDU) experience health complaints that may be associated with exposure to electric and magnetic fields. The most common are facial skin symptoms such as the sensation of burning, pricking, itching, stinging, and tightness. Symptoms of the eyes and symptoms of the nervous system, like headaches, dizziness, tiredness, and stinging sensations in the body, have been reported. At least some of these symptoms may be caused by, or aggravated also by, other factors in connection with VDU work. For instance, the visual properties may be important for eye symptoms. The possible association between exposure to electric and magnetic fields and such health symptoms are based on case reports $(1-4)$. Some epidemiologic studies have shown a correlation between skin symptoms and work with a VDU $(5-7)$.

In a previous investigation (8), we studied the effect on skin symptoms by reducing electric fields from the VDU at the subjects' workstations. One group of symptoms (tingling, pricking, or itching) was statistically significantly reduced by this interaction. The reduction, however, was small. The purpose of the current study was to see whether the results obtained in the first investigation could be reproduced. In addition, we wanted to study the effects on eye symptoms and on symptoms from the nervous system (headaches, fatigue, dizziness, etc). Thus the hypothesis tested was that skin symptoms, eye symptoms, and nervous system symptoms could be reduced

SINTEF Unimed, Trondheim, Norway. Current affiliation: Department of Physics, Norwegian University of Science and Technology, Trondheim, Norway.

2 Trondheim Bedriftshelsetjeneste, Trondheim, Norway.

3 Division of Occupational Medicine, University of Bergen, Bergen, Norway.

Reprint requests to: Dr Gunnhild Oftedal, Norwegian University of Science and Technology, Department of Physics, Lade, N7034 Trondheim, Norway. [E-mail: gunnhild.oftedal@phys.ntnu.no] 
by reducing the static and low-frequency fields of the VDU.

In order to increase the statistical power, we included more subjects than in the first study, and we increased the duration of the investigation period.

\section{Subjects and methods}

The study was designed as a controlled double-blind intervention study. Forty-two persons with relatively mild skin symptoms participated while working at their ordinary jobs. The electric fields from the VDU were reduced by mounting electric-conducting screen filters ( $\mathrm{Vu}$ Pro Tek ND 53) in front of the VDU. Two kinds of filters were used, "active" and "inactive". The inactive filters were identical to the active ones, but their ground cables had been replaced by empty plastic insulation. Measurements performed in the laboratory (9) showed that the transmission of electric fields up to $1000 \mathrm{kHz}$ was $2 \%$ or less for the active filters and $95-96 \%$ for the inactive filters. It was not possible to determine visually that the inactive filters were not grounded.

The study lasted for about 6 months. During the first week all the subjects worked with their VDU without using any filter. This week was followed by 3 months with an inactive filter and 3 months with an active filter, the order of use being determined by chance. The workers, and the research co-workers in contact with them, did not know which order was being used for each worker. The subjects only knew that they would use 2 kinds of filters.

During the investigation, there were 5 registration periods, each of them lasted for 5 days: the week when no filter was used, the fourth week with each filter, and the last week with each filter.

The study was approved by the Regional Committee for Medical Research Ethics, and permission for a person register was given by the Norwegian Data Inspectorate.

\section{Subjects}

Nine men and 33 women were selected for the study. They were between 24 and 62 years of age, the average being 41 years. They were selected on the basis of the results of a questionnaire distributed to companies and official institutions, a telephone interview with those screened by the questionnaire, and, finally, measurements of electric fields in front of the worker's VDU. The subjects should have had at least 1 facial skin symptom that had been reported in connection with VDU work (heat or burning sensation, stinging, tingling, prickling, itching, sensation of tightness or dryness, redness or flushing), and the symptoms should have occurred in connection with VDU work and not or to a less degree with other conditions. We required that the filter reduce the extremely low-frequency (ELF) or the very low-frequency (VLF) electric fields at the person's workstation by $40 \%$ or more when measured $0.6 \mathrm{~m}$ in front of the VDU. No subject should have used screen filters before they entered the study.

Individual registration periods with major changes influencing the electrical environment of the subject's workstation or the design of the study were excluded from the analysis. The resulting number of workers included for analysis for the registration period with no filter was 35. Reasons for exclusions were change of VDU after this period (1 subject), use of lightening tube close to the VDU ( 5 subjects), use of a screen filter in this period (1 subject). All the subjects $(\mathrm{N}=42)$ were included for the first registration period with the inactive filter as well as for the first registration period with the active filter. For the second registration period with the inactive filter 41 persons were included. One subject left the job before the last registration period. For the second registration period with the active filter 38 subjects were included. Two left the job and 2 changed to a new VDU before the last registration period.

\section{Electric and magnetic fields}

ELF and VLF electric fields were measured about $0.6 \mathrm{~m}$ in front of each person's VDU with an EMM-4 from Radians Innova $\mathrm{AB}$ that was not grounded. Before a person was eventually selected for the study, the electric fields from his or her VDU were measured without any filter and with an active filter (not the same as the one used in the actual investigation). The subject was present during the measurements, but no information was given about the various filters that would be used in the investigation.

After the last registration period, the electric fields were measured with no filter and with each of the 2 filters used in the investigation. In addition, the background fields were measured at the same position in front of the VDU with the VDU switched off. There was a great variation in the electric fields produced by the various units, and also in the reduction provided by the active filters. The ranges of the electric fields, as well as the median values, are shown in figure 1 . On the average, the electric fields measured in front of the VDU were slightly increased by the mounting of the inactive filters. The increase in electric fields by these filters was not, however, statistically significant. The differences between the inactive filters and active filters were statistically significant for both the ELF and VLF electric fields. For the ELF fields the difference varied from -2.0 to $18.0 \mathrm{~V} / \mathrm{m}$ with an average of $4.3 \mathrm{~V} / \mathrm{m}$, and for the VLF fields the variation was between -0.09 and $0.71 \mathrm{~V} / \mathrm{m}$ with an average of $0.23 \mathrm{~V} / \mathrm{m}$. 


\section{Registration of symptoms and physical and} psychosocial factors

During the registration periods at the end of each workday, the subjects filled out a questionnaire. They marked the severity of the symptoms (see table 2 in the Results section for a list of the symptoms) on a scale with 10 intervals and registered the time at work, the time in front of the VDU, the time working $2 \mathrm{~m}$ or nearer the VDU, the perceived room temperature, the work load, and the person's mood. For each day in a registration period, we also received information on outdoor temperature and humidity.

Another questionnaire was filled out by the subjects at the end of each registration period. For the whole registration period they summarized other physical and psychosocial factors that might influence the symptoms (eg, various indoor climate factors and social support at work). Furthermore, the subjects registered any major changes since the previous registration period with respect to study design or electric environment at his or her workplace.

At the beginning of the study, the subjects compared their VDU with and without any filter with respect to visual properties. The filter used for this comparison was not the same as the one used in the actual investigation, but the visual properties were identical. Measurements in a test laboratory (Institute of Optical Research, Royal Technical High School, Stockholm, 1991) showed that the filters reduced the luminance from a VDU with positive polarity by about $48 \%$ and thereby increased the contrast between the dark and light parts of the screen. The filters reduced both the diffuse reflectance and the specular reflectance. The values for the reflectance reductions were not established.

\section{Statistical methods}

The distribution of the data (degree of symptom) deviated significantly from normality. Therefore, statistical analyses were performed by Wilcoxon signed-rank tests. Paired comparisons between various registration periods and between different conditions were done with each person as his or her own control. A result was considered statistically significant when the statistical significance probability was $5 \%$ or less.

\section{Results}

\section{Visual effects of the filters}

With respect to visual reflexes and legibility, 32 subjects rated the screen with a filter as better than one without any filter, whereas 8 rated the 2 conditions as equal. With respect to comfort, almost all the workers $(\mathrm{N}=39)$ preferred the screen with a filter, and one evaluated the conditions as equal. (Two subjects did not participate in the evaluation of visual properties.)

\section{Physical and psychosocial factors versus registration periods}

The physical and psychosocial factors registered in the various registration periods were compared. For most factors no or very small variations were observed between the different periods. The factors showing the greatest variations are given in table 1 by including only subjects that were accepted for the registration period with no filter. Since more people were accepted for the periods when a filter was used, we also made a comparison of each pair of filter periods by including all the subjects accepted for both of these periods. The differences between any pair of filter periods were then equal to or less than suggested by table 1 . The greatest deviation from table 1 was obtained for outdoor temperature, for which the difference between each of the registration periods with an inactive filter and the first with an active filter was $0.2^{\circ} \mathrm{C}$.

\section{Symptoms in different registration periods}

In general, the symptoms were relatively mild. The highest average score obtained for any symptom was 3.4 , whereas the highest possible score was 9 . When the average was calculated, only persons having experienced a symptom at least once during the investigation period were included for that symptom. To give an overview of
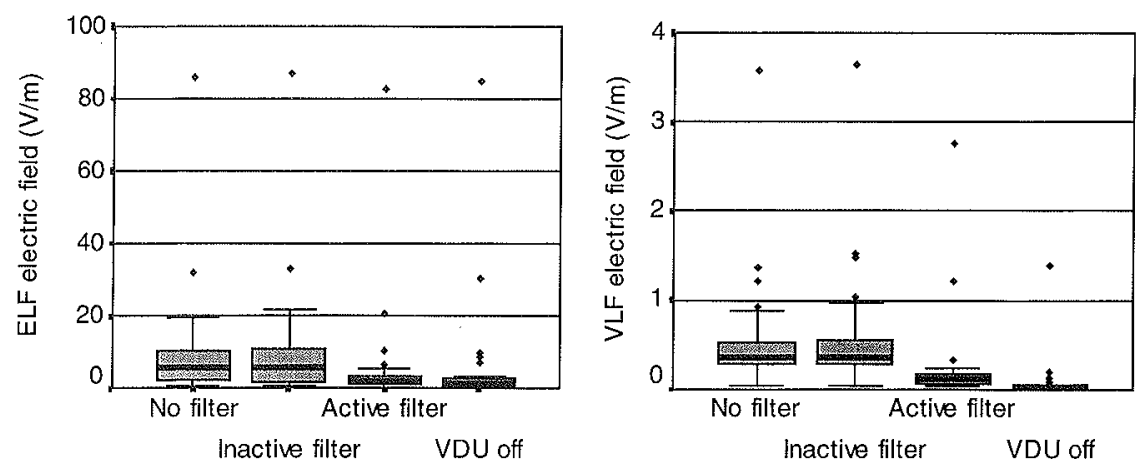

Figure 1. Electric fields measured 0.6 $\mathrm{m}$ in front of the subjects' video display units (VDU). The lower and the upper end of the boxes indicate the 25 and 75 percentile values, respectively. The horizontal lines dividing the boxes show the median values. The ends of the vertical lines indicate the highest and lowest value, respectively, that are not defined as outliers (values that are more than 1.5 boxlengths from the 75 percentile). The dots indicate the values of outliers. 
Table 1. Average values of factors showing variation between the registration periods. Only persons accepted for the analysis of the first registration period ( 35 subjects) are included. (VDU = visual display unit)

\begin{tabular}{|c|c|c|c|c|c|}
\hline \multirow[t]{3}{*}{ Factor } & \multirow[t]{3}{*}{ No filter } & \multicolumn{4}{|c|}{ Registration period } \\
\hline & & \multicolumn{2}{|c|}{ Inactive filter } & \multicolumn{2}{|c|}{ Active filter } \\
\hline & & $1^{\text {st }}$ & $2^{\text {nd }}$ & $1^{\text {st }}$ & $2^{\text {nd }}$ \\
\hline Workhours (h) & 7.0 & 6.8 & 7.1 & 6.9 & 7.1 \\
\hline $\begin{array}{l}\text { Time within } 2 \\
\text { meters of } \\
\text { the VDU (h) }\end{array}$ & 6.5 & 6.2 & 6.0 & 6.0 & 6.7 \\
\hline VDU time (h) & 4.8 & 4.6 & 4.6 & 4.5 & 4.9 \\
\hline $\begin{array}{l}\text { Outdoor } \\
\text { temperature } \\
\text { (average over day } \\
\text { and night) }\left({ }^{\circ} \mathrm{C} \text { ) }\right.\end{array}$ & 3.3 & 3.9 & 5.2 & 7.0 & 9.0 \\
\hline
\end{tabular}

symptom severity in the various registration periods, the mean value of all skin symptoms, of all eye symptoms, and of all nerve system symptoms has been plotted in figure 2 .

For all the symptoms the severity was almost constant during the different registration periods with filters, and there was no statistically significant difference between the periods with an active filter and the ones with an inactive filter. Nearly all the symptoms were more pronounced in the period with no filter than in any of the periods with a filter. For all the skin symptoms, for the majority of the eye symptoms, and for 2 of the nervous system symptoms these differences were statistically significant. See table 2 .

The difference in the effect on symptoms of the 2 filter periods may depend on the difference in their ability

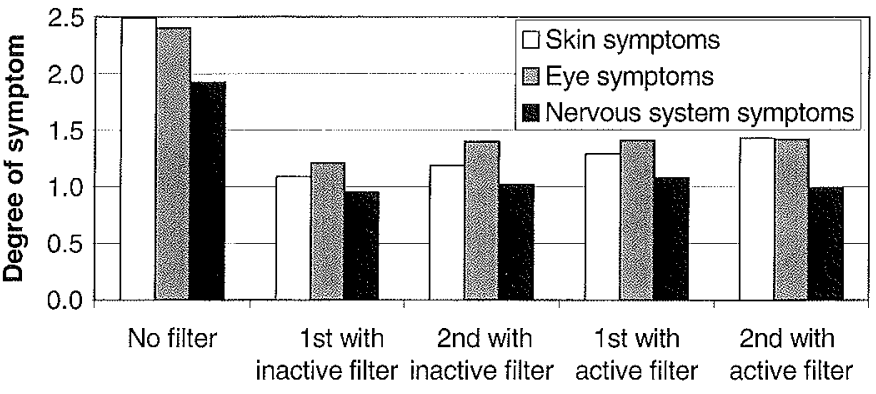

Registration period
Figure 2. Average severity of the symptoms registered during each of the 5 registration periods. Only subjects that registered the symptom at least once during all the periods are included.

Table 2. Comparison of symptom severity in the registration period without any visual display unit (VDU) filter with each of the registration periods with a filter. The number of subjects who registered the symptom at least once in any of the registration periods $(N)$, the number of subjects for which the symptom was the most pronounced in the period with no VDU filter $\left(N_{1}\right)$, and the number of subjects for whom the symptom was most pronounced in the specified period $\left(\mathrm{N}_{2}\right)$, and the significance probability (P-value) according to the Wilcoxon signed-rank test.

\begin{tabular}{|c|c|c|c|c|c|c|c|c|c|c|c|c|c|}
\hline \multirow[t]{4}{*}{ Symptoms } & \multirow[t]{4}{*}{$\mathrm{N}$} & \multicolumn{12}{|c|}{ Registration periods to which the period with no filter is compared } \\
\hline & & \multicolumn{6}{|c|}{ Inactive filter } & \multicolumn{6}{|c|}{ Active filter } \\
\hline & & \multicolumn{3}{|c|}{$1^{s t}$} & \multicolumn{3}{|c|}{$2^{\text {nd }}$} & \multicolumn{3}{|c|}{$1^{\text {st }}$} & \multicolumn{3}{|c|}{$2^{\text {nó }}$} \\
\hline & & $N_{1}$ & $\mathrm{~N}_{2}$ & $P$-value & $N_{1}$ & $\mathrm{~N}_{2}$ & P-value & $N_{1}$ & $\mathrm{~N}_{2}$ & P-value & $N_{1}$ & $\mathrm{~N}_{2}$ & P-value \\
\hline \multicolumn{14}{|l|}{ Skin } \\
\hline Heat, burning sensation, or stinging & 35 & 22 & 5 & $<0.001$ & 19 & 7 & 0.01 & 20 & 7 & 0.005 & 22 & 5 & $<0.001$ \\
\hline Tingling, prickling, or itching & 36 & 22 & 5 & 0.002 & 22 & 7 & 0.003 & 22 & 7 & 0.001 & 20 & 7 & 0.003 \\
\hline Sensation of tightness or dryness & 41 & 26 & 6 & $<0.001$ & 24 & 10 & 0.004 & 27 & 6 & $<0.001$ & 21 & 7 & $<0.001$ \\
\hline Redness or flushing & 33 & 17 & 5 & 0.003 & 17 & 9 & 0.01 & 18 & 9 & 0.03 & 17 & 6 & 0.02 \\
\hline \multicolumn{14}{|l|}{ Eye } \\
\hline Stinging or dryness & 38 & 22 & 8 & $<0.001$ & 21 & 8 & 0.007 & 20 & 9 & 0.01 & 17 & 7 & 0.005 \\
\hline Pain & 31 & 20 & 8 & 0.03 & 19 & 6 & 0.05 & 18 & 9 & 0.03 & 14 & 11 & 0.28 \\
\hline Redness & 31 & 15 & 5 & 0.04 & 16 & 8 & 0.13 & 14 & 6 & 0.13 & 10 & 11 & 0.68 \\
\hline Tiredness & 37 & 25 & 5 & $<0.001$ & 21 & 7 & 0.002 & 26 & 6 & $<0.001$ & 21 & 7 & $<0.001$ \\
\hline Light sensitivity & 33 & 20 & 2 & $<0.001$ & 18 & 4 & 0.002 & 18 & 5 & 0.004 & 17 & 5 & 0.01 \\
\hline \multicolumn{14}{|l|}{ Nervous system } \\
\hline Headaches & 39 & 23 & 8 & 0.004 & 18 & 12 & 0.09 & 20 & 11 & 0.09 & 17 & 10 & 0.03 \\
\hline Dizziness or vertigo & 30 & 13 & 9 & 0.14 & 13 & 9 & 0.14 & 13 & 8 & 0.05 & 10 & 7 & 0.08 \\
\hline Tingling in the body & 23 & 7 & 4 & 0.11 & 7 & 8 & 0.57 & 7 & 6 & 0.60 & 7 & 4 & 0.15 \\
\hline Tiredness or fatigue & 36 & 20 & 6 & $<0.001$ & 20 & 6 & 0.003 & 19 & 8 & 0.008 & 15 & 9 & 0.01 \\
\hline
\end{tabular}


to reduce the electric fields. Therefore, we also compared the various periods with a filter for the subjects having the greatest differences between the inactive and active filter periods (ELF: difference $>4 \mathrm{~V} / \mathrm{m}$ and relative difference $>40 \%$; VLF: difference $>0.2 \mathrm{~V} / \mathrm{m}$ and relative difference $>40 \%$ ). Even for this group (16 subjects) the symptoms were not more pronounced in the registration periods with inactive filters than in the registration periods with active filters.

To see how the symptoms varied with time, we analyzed separately the symptoms for those using the inactive filter first and for those using the active filter first. The symptoms were almost constant during the period of time the filters were used irrespective of the order in which the filters had been used.

\section{Symptoms versus other factors}

We analyzed the effect of factors registered every day during the registration periods. For instance, the symptom severity on days with a low outdoor temperature was compared with the symptom severity on days with a high outdoor temperature. For the other factors a similar comparison was done. Days with the presumably worst condition with respect to the actual factor were compared with days with the presumably best condition with respect to this factor. Regarding the analyses for each of the symptoms registered, statistical significance was reached for the following 3 comparisons only: (i) the degree of tired eyes was on the average 0.30 higher on days with long VDU time than on days with short VDU time, (ii) the degree of sensation of tight or dry skin was 0.35 higher on days with a low outdoor temperature than on days with a high outdoor temperature, and (iii) the degree of headache was 0.85 higher on days with a poor mood than on days with a good mood. The factors showing a variation between the different registration periods (table 1) are of particular interest. For these factors, the mean value of all the skin symptoms, all the eye symptoms, or all the nervous system symptoms did not show a statistically significant difference between the conditions compared.

\section{Discussion}

If electric fields have any effect on the symptoms registered in this study, the symptoms should have been less pronounced when the active filters were used than when the inactive filters were used. We did not observe any difference between the registration periods with the different filters, not even for persons for whom the difference with respect to electric fields between the 2 types of filters was greatest. A lack of any difference between the registration periods could have been caused by other factors making the conditions worse during active filter use than during inactive filter use. The analysis, however, shows that there was almost no difference between the various registration periods with filters with respect to most of the registered physical factors and psychosocial factors. Therefore, it is not likely that this negative finding can be explained by these factors.

Factors or random errors that were not controlled or registered in the study may also have been responsible for masking an eventual effect of reducing electric fields. This explanation is less likely because as many as 42 persons participated and because averaging was made over 5 registration days for each of the registration periods. For each of the filters used there were only minor differences in symptom severity between the first and last registration period separated in time by 2 months (see figure 2), and there was no systematic difference between the group using the active filter first and the group using the inactive filter first. These consistencies also contradict a suggestion of false negative results.

A study by Skuldberg et al (10) has suggested that static electric fields may be responsible for skin rashes due to aerosol deposits. Even though the static potential measured in front of the VDU in Skuldberg's study was relatively low, there were often strong "hot spots" at either side or the top of the plastic cover of the VDU. Measurements indicate that hot spots are important for the average electrostatic potential near the operator's face (11), and thus for aerosol deposits on the facial skin (12). The filters used in our study covered only the front of the VDU and had no effect on possible hot spots. Therefore, our study is not conclusive with respect to the potential effects of the electrostatic field.

It is not obvious why we could not confirm the result of the first investigation, namely, that 1 group of skin symptoms was less pronounced with the use of an active filter than with the use of an inactive filter (8). In the first study, the inactive and active filters were almost equal with respect to electrostatic fields. A smaller difference than in this study was also obtained for the ELF fields, whereas the difference for VLF fields was greater in the first study than in this one. It was also greater than for the group in this study for whom the difference between the 2 filters were the greatest. Whether the deviating results were due to the difference in VLF fields, to some unrecognized factor, or to the fact that some subjects were sensitive to electric fields in the first study but not in the second cannot be concluded.

The participating subjects were selected because of certain skin symptoms experienced in connection with VDU work. Some functional relation between these skin symptoms and the symptoms of the eyes or the symptoms of the nervous system cannot be excluded. Therefore, a generalization of the results to apply for all etiol- 
ogies of the symptoms registered in this study may not be possible.

By using filters, active as well as inactive, the degree of the symptoms was reduced by about $50 \%$ when compared with the condition when no filter was used. Because the electric fields were not reduced by using an inactive filter, there should be alternative explanations for the observed differences in symptoms. Both the time spent near the VDU and the time with VDU work was somewhat longer in the period without any filter than in most of the other registration periods. Furthermore, the outdoor temperature had the lowest average in the period with no filter. The analysis indicates that these factors had very small, if any, effect on the symptoms and therefore cannot be responsible for the observed difference in symptoms between the period without any filter and those with a filter.

In this study, as well as in the first study (8), the subjects evaluated the visual quality and comfort as improved by the filter. Whether the perceived improvement was only due to reduced reflexes, reduced luminance, increased contrast, or some other impact on visual factors has not been evaluated. Accordingly, some caution in generalization is warranted. In addition to a beneficial effect with respect to eye symptoms, reduced visual stress may have been a reason for a reduction of other symptoms. A study by Wilkins et al (13) indicates that flickering light from fluorescent tubes may give rise to eye symptoms, as well as headaches, and light with similar modulation frequencies is emitted from a VDU (14). In this context it is also interesting that patients with perceived electrical hypersensitivity seem to have a higher sensitivity to flickering light than referents when measured by visually evoked potentials (15). In addition psychological and organizational factors have been indicated to be risk factors for skin symptoms for people who work with a VDU (16).

In this study the subjects, or at least some of them, probably expected the symptoms to be reduced by a filter. Therefore, the placebo effect may have influenced the results. When placebos for medication are used, it has been shown that about a third of patients may have the sensation of pain reduced by at least $50 \%$. However, the placebo effect is reduced after a relatively short period of time (17). To some extent the effect of the filters may be explained by the placebo effect.

Another psychological effect that may have influenced the results is the Hawthorne effect. This effect is attributed to the attention and perceived care in association with intervention at workplaces, irrespective of the intervention itself (18). The effect has been studied for productivity and well-being and not for the specific symptoms registered in this study, but it is likely that people experiencing more well-being also focus less on symptoms. It was not possible to estimate the total role of the Hawthorne effect and that of the placebo effect in this study. Because the average symptom reduction for all the subjects was as large as $50 \%$, and the degree of symptoms was almost constant for the 6-month period with filter use, these psychological effects are probably not the only reasons for the reduction in symptoms observed during the use of the filters.

According to this study, and also to other studies, several physical and psychosocial factors may in general be the reasons for skin, eye, and nervous system symptoms experienced by VDU users, and probably electric or magnetic fields are generally not among these factors. On the other hand, we cannot exclude the possibility that there may be some persons, in this study and in general, for whom symptoms are provoked or aggravated by electric or magnetic fields.

\section{Concluding remarks}

This study does not support the hypothesis that skin, eye, or nervous system symptoms are reduced by reducing low frequency electric fields of the VDU. The study is not conclusive concerning static electric fields. Statistically significantly more pronounced symptoms in the period without any filter than in all the periods with a filter (active and inactive) can be explained by the filters' optical qualities and by psychological effects such as the placebo effect and the Hawthorne effect.

\section{Acknowledgments}

We would like to thank the members of the reference group of the project, Arnt Inge Vistnes, Håkon Lasse Leira, and Per Helmersen for their valuable advice during the planning of the investigation and in the presentation of the results.

The work was supported by The Work Environment Fund of the Confederation of Norwegian Business and Industry, The Research Council of Norway, Telenor A/ $\mathrm{S}$, and Static A/S.

\section{References}

1. Andersson M, Westlund L. Elöverkänslighet, kan det förebyggas? [May electrical hypersensitivity be prevented?]. Göteborg: Sunflex Datamiljö AB, 1991.

2. Knave B, Bergquist U, Wibom R. Symptom och subjektiva besvär vid "överkänslighet" mot elektrisitet [Symptoms and subjective complaints related to "hypersensitivity" to electricity]. Solna (Sweden): National Institute of Occupational 
Health, 1989. Investigation report 1989:4.

3. Nilsen A. Facial rash in visual display unit operators. Contact Dermatitis 1982;8:25-8.

4. Tjønn HH, Report of facial rashes among VDU operators in Norway. In: Pearce BG, editor. Health hazards of VDT's? Chichester (UK): John Wiley \& Sons, 1984:17-23.

5. Knave BG, Wibom RI, Voss M, Hedström LD, Bergqvist UOV. Work with display terminals among office employees, I: subjective symptoms and discomfort. Scand J Work Environ Health 1985;11:457—66.

6. Berg M. Facial skin complaints and work at visual display units: epidemiological, clinical, and histopathological studies [dissertation]. Stockholm: Karolinska Institute, July 1989.

7. Stenberg B, Hansson Mild K, Sandstöm M, Sundell J, Wall S. A prevalence study of the sick building syndrome (SBS) and facial skin symptoms in office workers. Indoor Air 1993;3:71-81.

8. Oftedal G, Vistnes AI, Ryggen K. Skin symptoms after the reduction of electric fields from visual display units. Scand J Work Environ Health 1995;21:335-44.

9. Anger G. Bildskärmsfilters förmåga att minska elektriska fält [The screen filters ability to reduce electric fields]. Stockholm: Statens strålskyddsinstitut, 1990. SSI-rapport 90-19.

10. Skyberg K, Skulberg K, Eduard W, Vistnes AI, Levy F, Djupesland P. Electric fields, dust and health problems among VDU-users in an office environment: an intervention program. In: Shrawan Kumar, editor. Advances in occupational ergonomics and safety: abstracts of XIIth Annual International Occupational Ergonomics and Safety Conference, Ypsilanti, Michigan, June 1998. Amsterdam: IOS press, 1998:8183.
11. Martinsen ACT, Vistnes AI. Static electricity: continuous recording of workers' electrical potential during a working day. In: Abstracts of twentieth annual meeting of Bioelectromagnetics Society; 1998 June 7-11; St Pete Beach, Florida. Frederick (MD): Bioelectromagnetics Society, 1998:161-2.

12. Wedberg WC. The influence of static electricity on aerosol deposition in indoor environments. Bergen: Christian Michelsen Institutt 1986. CMI publication no 373651-2.

13. Wilkins AJ, Nimmo-Smith I, Slater AI, Bedocs L. Fluorescent lighting, headaches and eyestrain. Light Res Technol 1989;21(1):11-8.

14. Andersson N, Sandström M, Berglund A, Hansson Mild K. Amplitude modulation of light from various sources. Light Res Technol 1994;26:157—60.

15. Sandström M, Lyskov E, Berglund A, Medvedev S, Hansson Mild K. Neurophysiological effects of flickering light in patients with perceived electrical hypersensitivity. J Occup Environ Med 1997;39(1):15-22.

16. Stenberg B, Eriksson N, Hansson Mild K, Höög J, Sandström $M$, Sundell J, et al. Facial symptoms in visual display terminal (VDU) workers: a case referent study of personal, psychosocial, building and VDT-related risk indicators. Int J Epidemiol 1995;24(4):796-803.

17. Kaada B. Placebo-gåten mot sin løsning? [The placebo effect will soon be solved?]. Tidsskr Nor Lægeforen 1986;106:635-41.

18. Homans GC. The human group. New York (NY): Harcourt, Brace, 1945.

Received for publication: 10 September 1998 